\title{
Modeling and Analysis of Induction Machines under Broken Rotor-bar Failures
}

\author{
$\mathrm{Pu}$ Shi \\ Engineering Department \\ Glyndwr University \\ Wrexham, UK
}

\author{
Zheng Chen \\ Engineering Department \\ Glyndwr University \\ Wrexham, UK
}

\author{
Yuriy Vagapov \\ Engineering Department \\ Glyndwr University \\ Wrexham, UK
}

\begin{abstract}
This paper discusses a novel method for motor fault detection under varying load conditions. Winding Function Approach (WFA) is used to develop a mathematical model to provide indication references for parameters under different load levels and different fault situations. Broken bar defects reference indexes are developed to assess rotor fault severity based on stator current and rotor speed. Stator current and rotor speed are used to demonstrate correlations between these parameters and broken rotor bar severity. Simulations and experimental results confirm the validity and effectiveness of the proposed approach.
\end{abstract}

\section{Keywords}

Induction machine, WFA, mathematical model, broken bar.

\section{INTRODUCTION}

Induction machines have been extensively used in industrial processes and have been playing a non-substitutable role in a variety of diverseindustries. Even though the design of the induction machine has been significantly improved in terms of both reliability and cost with the invention of the solid short circuited rotor structure, induction machines are still prone to failure sooner or later [1].

Furthermore, motors are often exposed to different hostile environments and variety conditions which can age the motor and make it subject to incipient faults. These faults, failures and gradual deterioration, can lead to motor failure if left undetected and their resulting unplanned downtime can prove very costly.Therefore, condition monitoring of electrical machines has received considerable attention for many years [2][3]. With proper condition monitoring system and fault detection schemes, the cost and period of maintaining motors can be greatly reduced and the overall availability of these machines can be significantly improved.

Many researchers have put their focuses on incipient fault detection and preventive maintenance for machine mechanical and electrical problem detection. Walliser have shown that when a bar is broken near an end ring, then significant interbar currents may flow between the broken and adjacent bars [4]. Ellison verified from tests carried out in an anechoiv chamber that slot harmonics in the acoustic noise spectra from a small power induction motor [5]. Verma and Morita have studied the changes in the air-gap field as a function of static eccentricity using search coils in the stator core [6][7].

In this study, a versatile and novel method for predicting the dynamic performance of induction machines which can be used in model-based diagnosis is presented. The effects of rotor broken bars on the machine stator current and rotor speed signature under varying load conditions are discussed.

\section{COUPLED-CIRCUIT MODEL OF INDUCTION MACHINE}

ForaWinding Function Approach (WFA) model which accounts for all the space harmonics in the machine, the differential equations predicting the performance of an $\boldsymbol{m}$ phase induction machine with $\boldsymbol{n}$ rotor bars are derived in[8][9][10][11]. This model is adopted the coupled magnetic approach by assuming the current in each rotor bar as an independent variable. This approach has been successful applied to predict the performance of induction and synchronous reluctance machines including space and time harmonics by taking into multiple phases and general winding connections such as concentrated, concentric and multiple layers with different pitch factor [9].

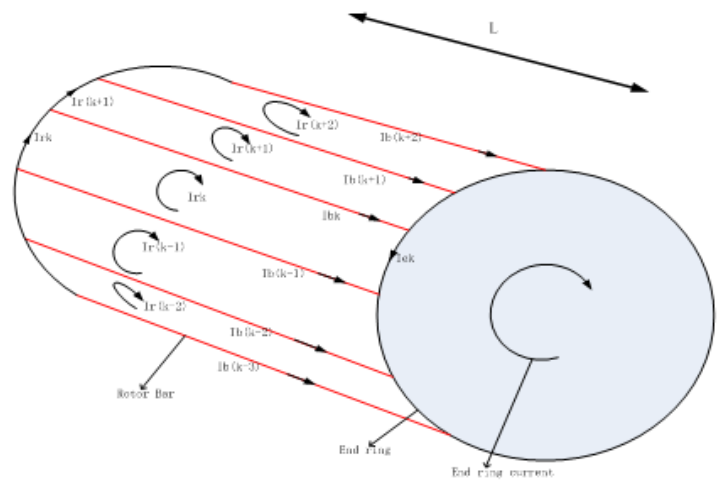

Fig1. Elementary rotor loops and current definitions

The analysis is considered initiallywith the following assumptions [8]:

(1) The machine is symmetric;

(2) M identical stator windings with axes of symmetry ;

(3) The air-gap is uniform and smooth;

(4) $\mathrm{N}$ uniformly distributed cage bars or identical rotor windings with axes of symmetry such that even harmonics of the resulting spatial winding distribution are zero;

(5) The saturation and skin effect are neglected;

(6) The rotor bars are insulated from the rotor andthere is no inter-bar current flows through the laminations;

(7) The permeability of machine armatures is assumed infinite; 
(8) The eddy current, friction, and windage losses are neglected.

\subsection{Stator Voltage Equations}

An induction machine stator comprises ofm phase concentric windings.Each of these windings is treated as a separate coil[9]. The stator equations for aninduction machine can be written in vector matrix form as [8][9]:

$$
\left[V_{s}\right]=\left[R_{s}\right]\left[I_{s}\right]+\frac{d}{d t}\left[\Phi_{s}\right]
$$

where:

$$
\left[\Phi_{s}\right]=\left[L_{s s}\right]\left[I_{s}\right]+\left[L_{s r}\right]\left[I_{r}\right]_{(2)}
$$

The matrix $\left[R_{s}\right]$ is a 3 by 3 diagonal matrix which consists of resistances of each coil.

Due to conservation of energy, the matrix $\left[L_{s s}\right]$ is a symmetric $3 \times 3$ matrix. The mutual inductance matrix $\left[L_{s r}\right]$ is a $3 \times n$ matrix comprised of the mutual inductances between the stator coils and the rotor loops.

$$
\left[L_{s r}\right]=\left[L_{r s}\right]^{T}=\left[\begin{array}{lllll}
L_{s r 11} & L_{s r 12} & \cdots & L_{s r 1 n} & L_{s r l e} \\
L_{s r 21} & L_{s r 22} & \cdots & L_{s r 2 n} & L_{s r 2 e} \\
L_{s r 31} & L_{s r 32} & \cdots & L_{s r 3 n} & L_{s r 3 e}
\end{array}\right]
$$

\subsection{Rotor Voltage Equations}

A cage rotor consists of $\boldsymbol{n}$ bars can be treated as $\boldsymbol{n}$ identical and equally spaced rotor loop.As illustrated in Figure 1, each loop is formed by two adjacent rotor bars and the connecting portions of the end-ring between them. Hence, the rotor circuits have $n+1$ independent current as variables. The nrotor loop currents are coupled to each other and to the stator windings through mutual inductances. The end-ring loop does not couple with the stator windings, it however couples the rotor currents only through the end leakage inductance and the end-ring resistance [9][11].

From Figure 2, the voltage equations for the rotor loops can be written in vector matrix form as[8][9]:

$$
\left[V_{r}\right]=\left[R_{r}\right]\left[I_{r}\right]+\frac{d}{d t}\left[\Phi_{r}\right]
$$

Where

$$
\left[V_{r}\right]=\left[\begin{array}{lllll}
V_{r 1} & V_{r 2} & \cdots & V_{r n} & V_{r e}
\end{array}\right]^{T}
$$

In case of a cage rotor, the rotor end ring voltage is $V_{r e}=0$, and the rotor loop voltages are $V_{r k}=0,(k=1,2 \ldots n)$.

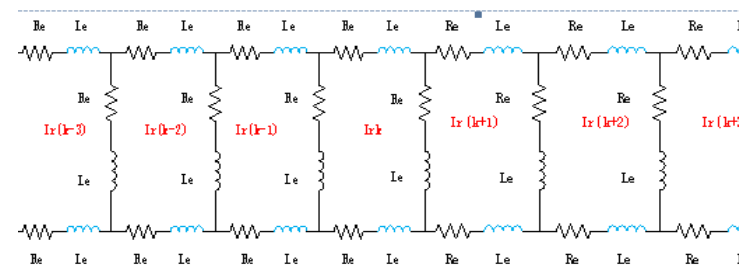

Fig2.Rotor cage equivalent circuit showing rotor loop currents and circulating end ring current.

Since each loop is assumed to be identical, the equation (4) is valid for every loop. Therefore the resistance matrix $\left[R_{r}\right]$ is a symmetric $(n+1)$ by $(n+1)$ matrix given by:
$\left[R_{r}\right]=\left[\begin{array}{ccc}2\left(R_{b}+R_{e}\right) & -R_{b} & 0 \\ -R_{b} & 2\left(R_{b}+R_{e}\right) & -R_{b} \\ \vdots & \vdots & \vdots \\ \vdots & \vdots & \vdots \\ 0 & 0 & 0 \\ -R_{b} & 0 & 0 \\ -R_{e} & -R_{e} & -R_{e}\end{array}\right.$

In relation (4), the rotor flux can be written as:

$$
\left[\Phi_{r}\right]=\left[L_{r s}\right]\left[I_{s}\right]+\left[L_{r r}\right]\left[I_{r}\right]
$$

Where the matrix $\left[L_{r s}\right]$ is the transpose of the matrix $\left[L_{s r}\right]$.Due to the structural symmetry of the rotor, $\left[L_{r r}\right]$ can be written in matrix form (8), where $L_{k k}$ is the self-inductance of the $k t h$ rotor loop, $L_{b}$ is the rotor bar leakage inductance, $L_{e}$ is the rotor end-ring leakage inductance and $L_{k i}$ is the mutual inductance between two rotor loop.

$\left[L_{r r}\right]=\left[\begin{array}{ccccccc}L_{11}+2\left(L_{b}+L_{e}\right) & L_{12}-L_{b} & L_{13} & \cdots & L_{1(n-1)} & L_{1 n}-L_{b} & -L_{e} \\ L_{21}-L_{b} & L_{21}+2\left(L_{b}+L_{e}\right) & L_{23}-L_{b} & \cdots & L_{2(n-1)} & L_{2(n-1)} & -L_{e} \\ \vdots & \vdots & \vdots & \cdots & \vdots & \vdots & \vdots \\ \vdots & \vdots & \vdots & \cdots & \vdots & \vdots & \vdots \\ L_{(n-1) 1} & L_{(n-1) 2} & L_{(n-1) 3} & \cdots & L_{(n-1)(n-1)}+2\left(L_{b}+L_{e}\right) & L_{(n-1) n}-L_{b} & -L_{e} \\ L_{n 1}-L_{b} & L_{n 2} & L_{n 3} & \cdots & L_{n(n-1)}-L_{b} & L_{n n}+2\left(L_{b}+L_{e}\right) & -L_{e} \\ -L_{e} & -L_{e} & -L_{e} & \cdots & -L_{e} & -L_{e} & n L_{e}\end{array}\right]$ (8)

\subsection{Calculation of Torque}

The mechanical equation of motion depends upon the characteristics of the load which may differ widely from one application to the next. An assumption is made here for simplicity, which the torque which opposes that produced by the machine consists only of an inertial torque and an external load torque which are known explicitly.

In this case the mechanical equation of the machine is[8][9]:

$$
T_{e m}-T_{L}=J \frac{d \Omega_{m}}{d t}
$$

where $T_{e m}$ is the electromagnetic torque produced by the machine, $T_{L}$ is the load torque, $J$ is the inertia of the rotor and $\Omega_{m}$ is the mechanical speed.

With

$$
\Omega_{m}=\frac{1}{P} \frac{d \theta}{d t}
$$

The electrical torque can be found from the magnetic coenergy $W_{c o}$ as 


$$
T_{e}=\left(\frac{\partial W_{c o}}{\partial \theta_{r m}}\right)_{\left(I_{s}, I_{r} c o n s \tan t\right)}
$$

In a linear magnetic system the coenery is equal to the stored magnetic energy so that,

$$
W_{c o}=\frac{1}{2} I_{s}^{t} L_{s s} I_{s}+\frac{1}{2} I_{s}^{t} L_{s r} I_{r}+\frac{1}{2} I_{r}^{t} L_{r} I_{s}+\frac{1}{2} I_{r}^{t} L_{r r} I_{r}
$$

It is obvious that $L_{s s}$ and $L_{r r}$ contain only constant elements and $T_{e}$ is a scalar quantity. Therefore the electromagnetic torque is finally given by the following equation[8][9]:

$$
T_{e m}=P I_{s}^{t}\left\{\frac{d}{d \theta}\left[L_{s r}\right]\right\} I_{r}
$$

where $\theta$ is the angular position of the rotor and $P$ denotes the number of motor pole pairs.

\subsection{Calculation of Inductances}

It is apparent that the calculation of all the machine inductances as defined by the inductances matrices in the previous section is the key to the successful simulation of an induction machine.

These magnetizing and mutual inductances that are relevant to the machine inductances are conveniently calculated by means of Winding Function Approach. The WFA assumes no symmetry in the placement of any motor coil in the slots. According to winding function theory, the mutual inductance between two windings $i$ andjin any electric machine can be computed by the following equation[12][13][14]:

$$
L_{i j}\left(\theta_{r}\right)=\frac{\mu_{0} l r}{g} \int_{0}^{2 \pi} N_{i}(\theta, \Phi) N_{j}(\theta, \Phi) d \Phi
$$

where $\mu_{0}=4 \pi \cdot 10^{-7} \mathrm{H} / \mathrm{m}, \mathrm{g}$ is the air gap length, $\theta_{r}$ is the rotor angular position, $r$ is the average radius of the air gap, $l$ is the active stack length of the motor, $\Phi$ is a angular position along the stator inner surface, and $N_{i}(\theta, \varphi), N_{j}(\theta, \varphi)$ is called the winding function of circuit $i$ and $j$ and represents the magneto motive force $(M M F)$ distribution along the air gap for a unit current flowing in winding.

The $\boldsymbol{n}$ rotor loop currents are coupled to each other and to the stator winding through the mutual inductances obtained from (14). However, the end-ring loop current does not couple with the stator windings[11]. The end-ring loop couples with the rotor loop currents only through the end-ring leakage inductance and the end-ring resistance [13]. The flux created by the end-ring currents is orthogonal to the flux radiated from the stator windings. The end-ring flux cannot contribute the rotating force of the rotor. Therefore, the mutual inductance between the stator winding and the end-ring is obtained as

$$
L_{s r k e_{l}}\left(\theta_{r}\right)=0
$$

Where $k$ means one stator winding of the three phases (a, b, c) and $e_{l}$ is one of the two end-rings $\left(\mathrm{e}_{1}, \mathrm{e}_{2}\right)$.

Table 2. Specifications of an Induction Machine

\begin{tabular}{|c|c|}
\hline Specifications & Value \\
\hline Rated Power & $3.7 \mathrm{~kW}$ \\
\hline Horse Power & $5 \mathrm{HP}$ \\
\hline Input Voltages & $220 / 380 \mathrm{~V}$ \\
\hline Input Currents & $13.8 / 8.0 \mathrm{~A}$ \\
\hline Pole pairs & 2 \\
\hline Frequency & $50 \mathrm{~Hz}$ \\
\hline Speed & $3000 \mathrm{rpm}$ \\
\hline $\begin{array}{c}\text { Number of Stator } \\
\text { Slots }\end{array}$ & $36 \mathrm{EA}$ \\
\hline $\begin{array}{c}\text { Number of Rotor } \\
\text { Bars }\end{array}$ & $28 \mathrm{EA}$ \\
\hline
\end{tabular}

The specifications of the induction machine simulated in this paper listed in Table 1. The induction machine has a stator comprises of three phase concentric winding with 36 slots, 28 squirrel cage rotor bars and two coils per phase.Each coils is constituted of three sections having $N_{s}$ turns in series. Figure 3 (a) shows the winding distribution of the stator phase. The MMF distribution of the stator phase is represented by the winding function in Figure 3 (b)[15]. From Figure 3 the winding distributions and winding functions of other stator phase are obtained by produced by $2 \pi / 3$ and $4 \pi / 3$ phase shift, respectively.

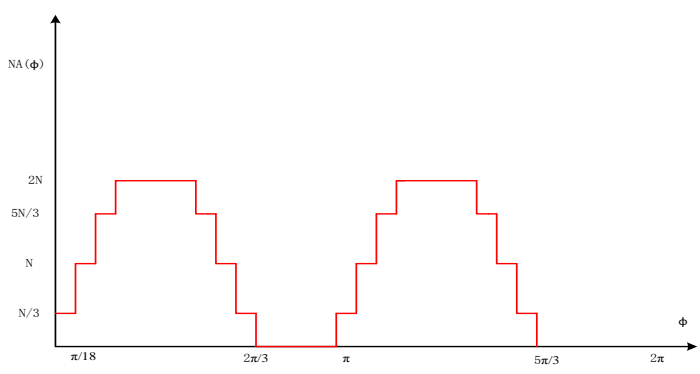

(a)

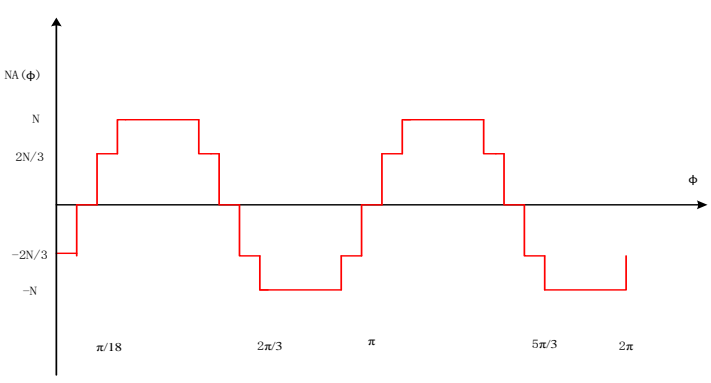

(b)

Fig 3.Stator-winding graph. (a) Winding distribution. (b) Winding function. 


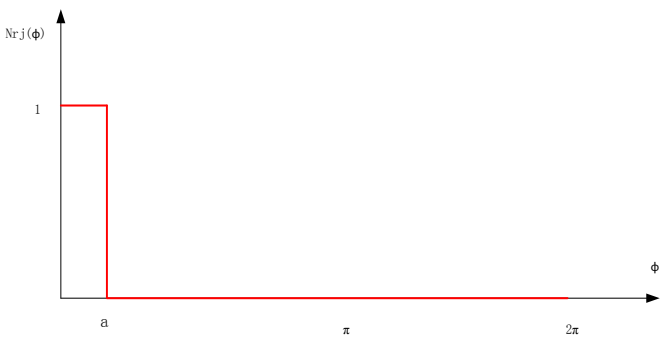

(a)

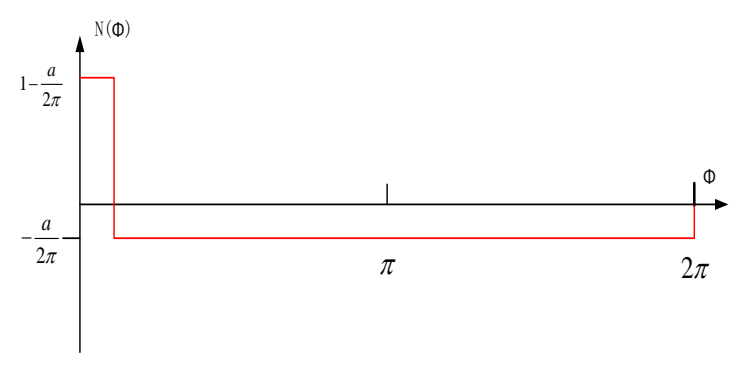

(b)

Fig 4.Rotor-winding graph. (a) Winding distribution. (b) Winding function.

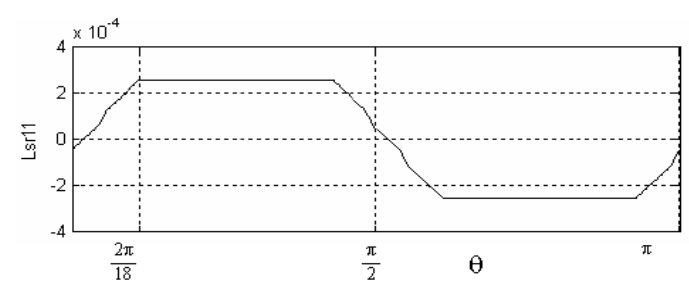

Fig 5. Stator-rotor mutual inductance between the stator phase " 1 "and rotor loop " 1 "

The MMF distribution produced by stator current through a rotor loop can only take two values depending on whether they are inside or outside the loop. The angle between two adjacent rotor bars is $\mathrm{a}=\pi / 14$ according to (20), the MMF distribution produced by $1 \mathrm{~A}$ of current through the first rotor loop, is shown in Figure 4.Figure 4 demonstrates the winding distribution and winding function of the rotor loop. To obtain the winding distribution and winding function of the next rotor loop, the graphs in Figure4(a) and (b) should be shifted to the positive angle $a$ as

$$
a=\frac{2 \pi}{N}
$$

Where $a$ is the radian angle between two adjacent rotor bars and $N$ is the number of rotor bars.

The mutual inductance between stator and rotor brancheswill be a function of the rotor position angle, $\theta$. Figure 5 gives the mutual inductance $\left(L_{s r l l}(\theta)\right)$ between the stator phase "l" and the rotor loop " 1 ". Note that the mutual inductance between the phase "2" and the rotor loop "l" is $L_{s r l l}(\theta)$ but shifted to the right by $6 \gamma$, where $\gamma$ is theangle between two stator slots. Mutual inductance between the phase " $l$ " and the rotor loop " 2 " is $L_{\text {srll }}(\theta)$ but shifted to the left by $\alpha$, where $\alpha$ is the angle betweentwo rotor bars.

\section{SIMULATION AND ANALYSIS}

To validate the proposed model, a functional schema of the induction machine was developed based on the Matlab platform. The machine was first simulated under healthy condition. Then, the rotor failures under one, two and three continuous broken bars were simulated.

When induction machine operate under ideal, healthy circumstances, stator current issinusoidal signal. However, in practical unexpected distortions and noises exist in stator current, which make it difficult to accuratedetect and diagnosis faults. In this research, simulations under ideal conditions are assumedto acquire accurate broken rotor bar faults affected signal.

Figure 6illustrates the stator phase currents of the induction machine during steady state for the case of the balanced sinusoidal voltage supply. From top to bottom, 0\%, 20\%, $40 \%, 60 \%$ and $100 \%$ load level cases were simulated. Stator currents increasing are clearly observeddue to load levels rising.So, under healthy machine condition, increasing the load levels has a direct influence to the stator current amplitudes.

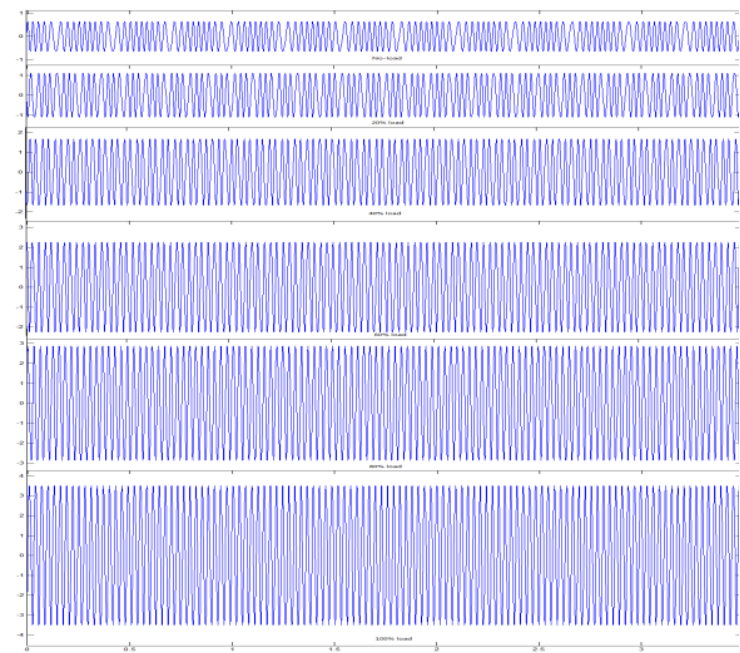

Fig6. Healthy induction motor stator current under different load level.

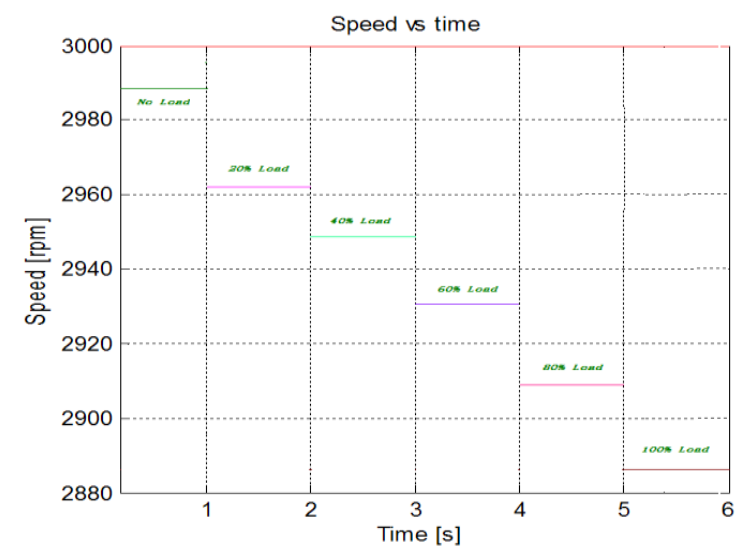

Fig7. Healthy induction motor rotor speed under different load level.

Figure 7 shows the steady state speed of the machine under the same conditions as Figure 6. In this case, rotor speed decreases along with load increscent. Rotor speeds change 
from the $2998 \mathrm{rpm}$ at no load to 2962, 2947, 2933, 2912 and 2888 at $20 \%, 40 \%, 60 \%, 80 \%$ and $100 \%$ load level.

Figure $6 \& 7$ depict load level affects to induction machines under healthy condition. Load level raising causes stator current increase and rotor speed decrease. Table 2 lists detail values of the stator current and speeds values under different load levels.

Rotor bar faultsare discussed in this paper by including proper relationships between the rotors current variables and reducing the coupling inductance matrix. If the bar between loop $k$ and $\operatorname{loop}(k+1)$ is an open circuited, then $I_{r k}=I_{r(k+1)}$ is required,which means that the current $I_{r k}$ flowing in a double width loop as shown in Figure 8[9].

When broken bar fault occurs in rotor, negative component at frequency $(1-2 s) f$ is generated in stator current. This component produces a torque ripple and causes rotor speed variation. This speed variation cause mechanical angular variation and lead to motor produces a phase modulation in the stator flux.

Table 2. Healthy induction machine current and speed under different load level

\begin{tabular}{|c|c|c|}
\hline $\begin{array}{c}\text { Load Level } \\
\text { (Percentage) }\end{array}$ & $\begin{array}{c}\text { Stator Currents } \\
\text { (A) }\end{array}$ & $\begin{array}{c}\text { Rotor Speed } \\
\text { (RPM) }\end{array}$ \\
\hline No Load & 0.64 & 2998 \\
\hline $20 \%$ & 1.17 & 2962 \\
\hline $40 \%$ & 1.8 & 2947 \\
\hline $60 \%$ & 2.4 & 2933 \\
\hline $80 \%$ & 2.9 & 2912 \\
\hline $100 \%$ & 3.6 & 2888 \\
\hline
\end{tabular}
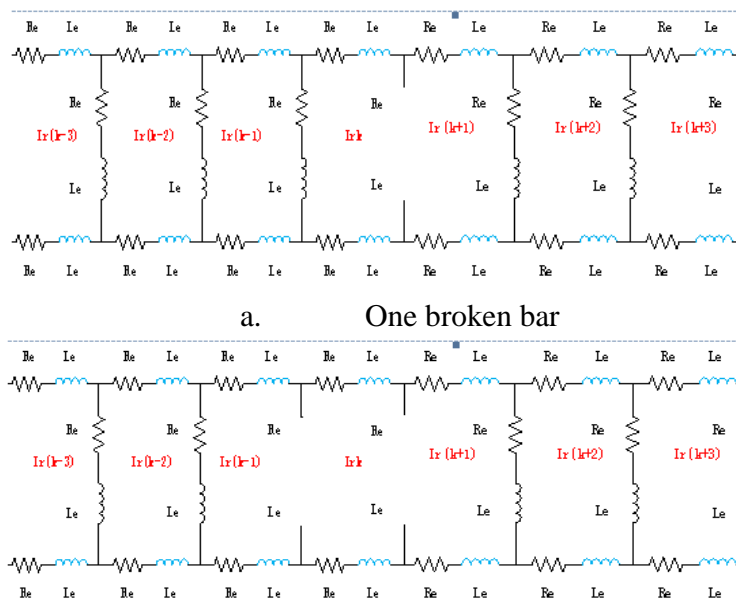

b. Two broken bars

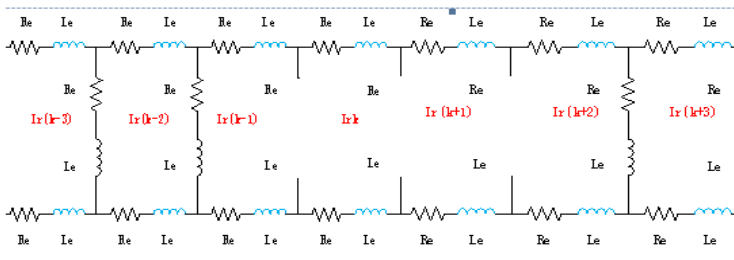

c. Three broken bars

Fig8. Winding circuits representation of one broken rotor bar.

The broken barcase is impressed on the inductance matrix $\left[L_{r r}\right]$ by adding the column relating to $I_{r k}$, meaning the column $k$ to that relating to $I_{r(k+1)}$ which is the column $k+1$. The same relationship is applied to the corresponding rows. Similar measures are taken for the resistance matrix $\left[R_{r}\right]$. The same process is done on the column of mutual inductance $\left[L_{s r}\right]$. Furthermore open circuited bars are incorporated by repeating the above mentioned reduction process, as required[8].

An obviously symptom about rotor bar breakage is rotor bar resistance will increase along with bar broken severity level. Broken rotor bars simulation under software normally run by increasing bar resistance trying to mimic the real current flow situation. Figure 8 (a)shows a case of one rotor bar totally disconnected, which means no current will flow through it. This extremely scenario will help to analysis how rotor broken bars affect stator current and rotor speed as shown in Figure 9 and 10 .

Figure $9 \& 10$ show the steady state phase boundary currents and speed of the machine for the case of the one to three broken bars with a balanced sinusoidal voltage supply under no load level. Comparing to Figure $6 \& 7$, ripples exist in the machine phase currents and speeds under a different broken bars become noticeable as more broken bars added. However, these symptoms are not obvious enough to diagnosis by observing the figures especially under low load level. As shown in Figure 10,rotor speed fluctuate around 2988 $\pm 2 \mathrm{rpm}$, these cannot be sensed by bare eyes even ordinary sensor. Hence, the detection of broken rotor bars under low load level is not an easy task, nevertheless, it is essential to be able to model the effects of broken rotor bars for accurate prediction of both the transient and steady state conditions for determination of phase current and speed.

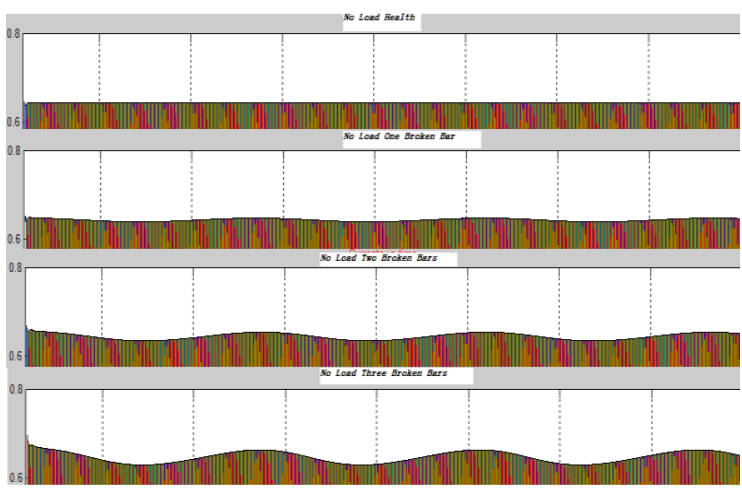

Fig 9.Broken under no load level.

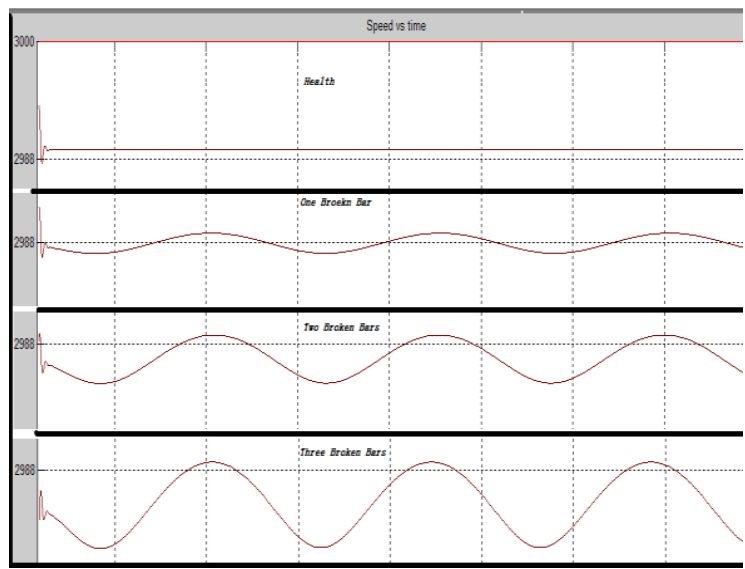

Fig10.Broken under no load level.

Figure $11 \& 12$ depict the steady state phase currents and speeds of the machine for the case of $80 \%$ load under 
different broken bars with a balanced sinusoidal voltage supply. Comparing to Figure $6 \& 7$ and Figure $9 \& 10$, stator phase currents and rotor speeds keep decreasing under same load level due to more broken rotor bars fault occurs. The riffles caused by broken rotor bar fluctuate more and more obviously.

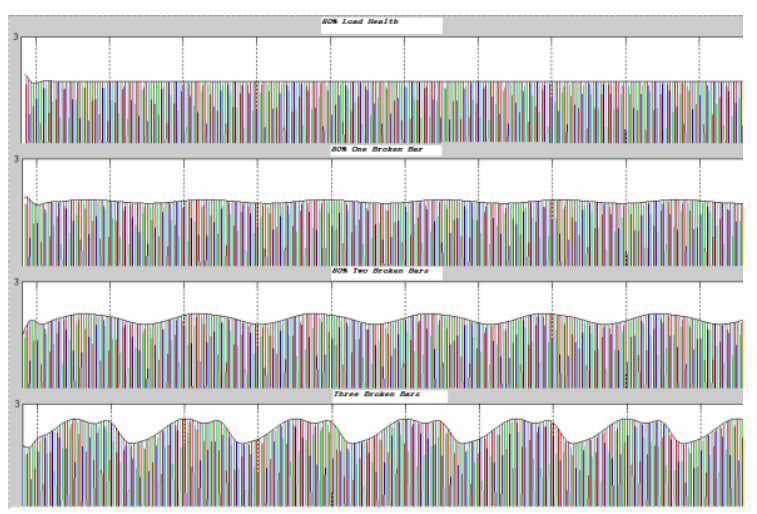

Fig11. Two broken rotor bars induction motor stator current under different load level.

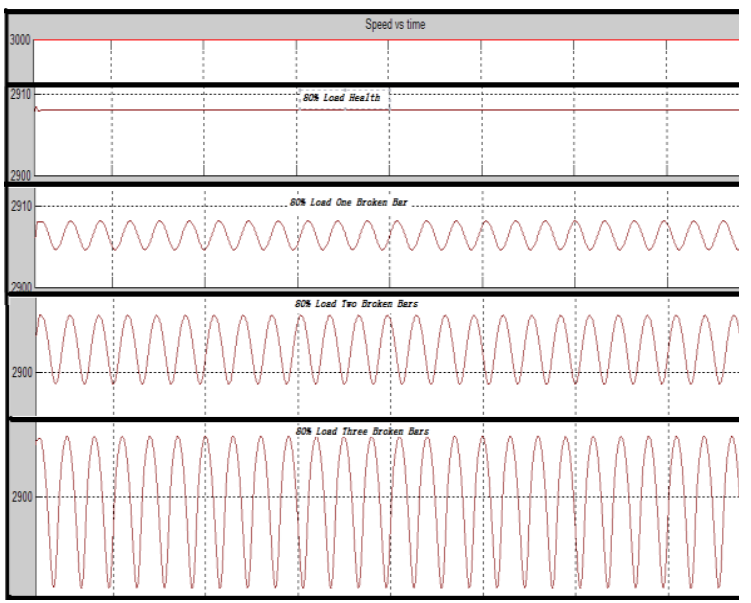

Fig12. Two broken rotor bars induction motor rotor speed under different load level.

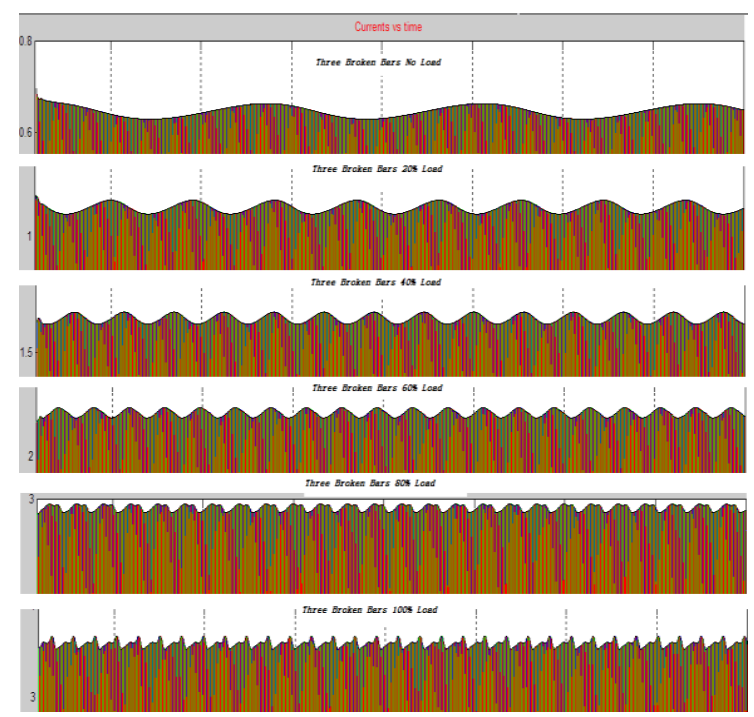

Fig13. Three broken rotor bars induction motor stator current under different load level.

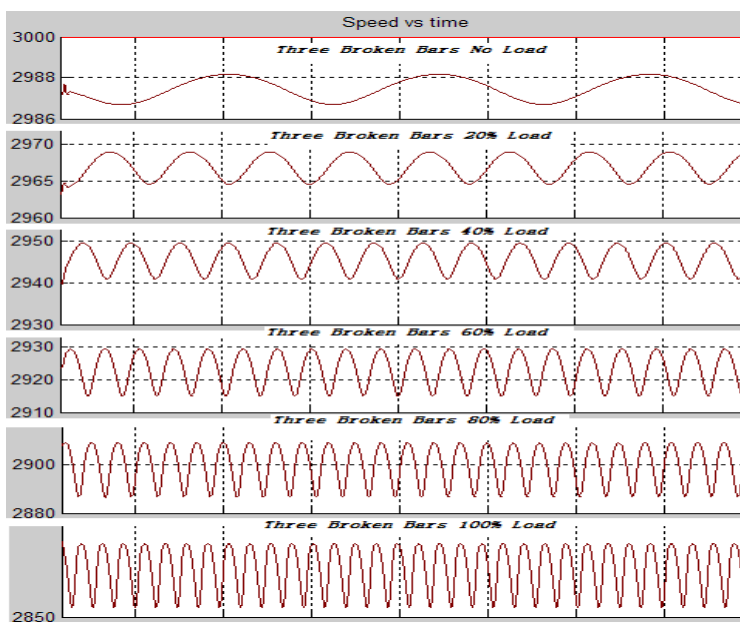

Fig14. Three broken rotor bars induction motor rotor speed under different load level.

Figure 8 (c) shows the winding circuit of three broken bars. Figure $13 \& 14$ illustrate the phase currents and speeds of the machine for the case of three broken rotor bars during steady state with a balanced sinusoidal voltage supply. It can be observed that the effect of three broken bars on the machine phase currents and speeds in the steady state are very noticeable.

\section{FAULT DETECTION APPROACH}

Through previous discussion, a special relationship between number of broken bars, rotor speed, load level and stator current is developed. Stator current and rotor speed decrease with load level increase regardless operate condition. But these wave fluctuations come with fault severity and load level, more fault happen in the rotor high magnitude and period fluctuations will show up.

Table 3. Simulation result analysis based on mean and SD values

\begin{tabular}{|c|c|c|c|c|c|c|}
\hline & No Load & $20 \%$ & $40 \%$ & $60 \%$ & $80 \%$ & $100 \%$ \\
\hline Mean abs & 0.272 & 0.4625 & 0.7023 & 1.0093 & 1.3063 & 1.5923 \\
\hline Standard Deviation & 0.4543 & 0.7813 & 1.177 & 1.699 & 2.191 & 2.677 \\
\hline SO/Mean abs & 1.670220588 & 1.689297297 & 1.675921971 & 1.683344892 & 1.677256373 & 1.681215851 \\
\hline
\end{tabular}

(a) Healthy

\begin{tabular}{|c|c|c|c|c|c|c|}
\hline \multicolumn{7}{|c|}{ Onebrolenhar } \\
\hline & Noload & $20 \%$ & $40 \%$ & $60 \%$ & $80 \%$ & $100 \%$ \\
\hline Mean abs & 0.3235 & 0.5563 & 0.8568 & 1.136 & 1.445 & 1.7578 \\
\hline Standard Deviation & 0.5516 & 0.7818 & 1.179 & 1.001 & 2.03 & 2.475 \\
\hline SO/Mean abs & 1.405555023 & 1.405356822 & 1.4089388915 & 1.409330966 & 1.48855599 & 14080000013 \\
\hline
\end{tabular}

(b) One broken bar Twoborolenbar

\begin{tabular}{|c|c|c|c|c|c|c|}
\hline & Noload & $20 \%$ & $40 \%$ & $60 \%$ & $80 \%$ & $100 \%$ \\
\hline Meandabs & 0.339 & 0.5728 & 0.5958 & 1.1977 & 1.456 & 1.8288 \\
\hline Standard Deviation & 0.6641 & 0.7818 & 1.171 & 1.603 & 204 & 2501 \\
\hline SO/Mean boss & 1.360026559 & 13648743302 & 1361944638 & 1361937128 & 1364010107 & 1.3675334 \\
\hline
\end{tabular}

(c) Two broken bars Threebrokenbar

\begin{tabular}{|c|c|c|c|c|c|c|}
\hline \multicolumn{7}{|c|}{ minct von } \\
\hline & Noload & $20 \%$ & $40 \%$ & $60 \%$ & $80 \%$ & $100 \%$ \\
\hline Mean abs & 0.347 & 0.5978 & 0.955 & 1.229 & 1,5955 & 19135 \\
\hline Standard Devisition & 0.4566 & 0.7864 & 1.188 & 1.618 & 2027 & 2513 \\
\hline SO/Mean abs & $13.15850,144$ & 133549013 & 1311188233 & 1316551794 & 1316661254 & 1313302035 \\
\hline
\end{tabular}

(d) Three broken bars 
Table 3 shows the mean abs values and standard deviation values of induction under different operation condition. From Table 3 mean $a b s$ and $S D$ both increase with load level no matter under what work conditions. It is hard to make any decision based on these two values. To solve this problem, a specified fault index equation (17) is put forward

$$
\text { Index }=\frac{S D}{\text { Meanabs }}
$$

Where SD represents standard deviation, Meanabs represents mean absolute values.

By calculating the fault index equation in (17), it is much easier to judge the induction machines condition. As shown in Table 3(a), under healthy situation this index is around 1.67. Under one broken rotor bar occurs in this induction machine, this index will drop to 1.40 as shown in Table 3(b). As more rotor bars breakage happen, the index will continue drop to 1.36 and 1.31 under two and three broken bars.

From Table 3, a special relationship between load level and stator current has developed. Through index equation (17), accurate induction machine operation condition can be evaluated regarding the load level.

\section{EXPERIMENTAL TEST AND \\ RESULTS}

In order to test and verify the conclusiondrown up in the previous part, a whole experimental set based on the proposedsystem will be configured. The experiment was carried out under the self-designed test rig which is mainly composed of three phase induction machines, current transducer, A/D converter, and computer. Firstly, transient current signalswere collected from testedmotors and signal preprocessing was conducted which containssmoothing and subtraction. Moreover, WaveletTransform (WT) was used to decompose the acquired time domain signal into timefrequency domain. Then, fault features frequency $(1+2 s) f$ was extracted from WT transform. Finally, the individual diagnosis results were used to validate the developed model.

The characteristics of the 3 phase induction machines used in this experiment are listed in Table 1. Among these tests, one isnormal (healthy), which was set as a benchmark conditioncompared with another faulty motor with three broken rotor bars. A current Hall Effect sensor was placed in one of the line current cables. The stator current was sampled with a $1 \mathrm{kHz}$ rate and interfaced to a PC by an ADC-11 acquisition board.

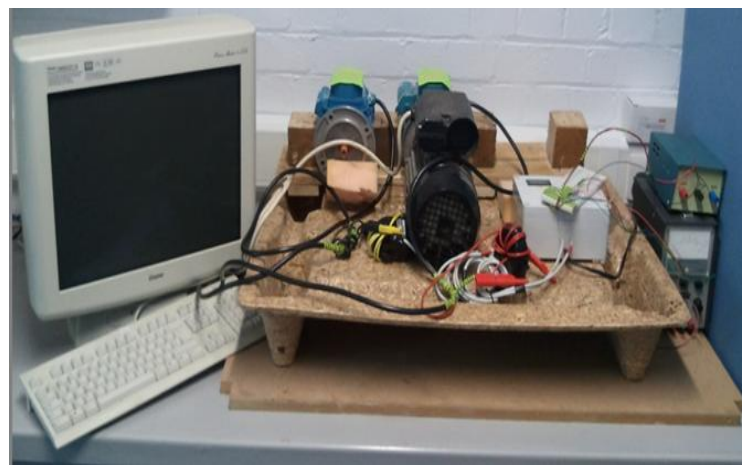

Fig15. View of the experimental setup and broken rotor bars

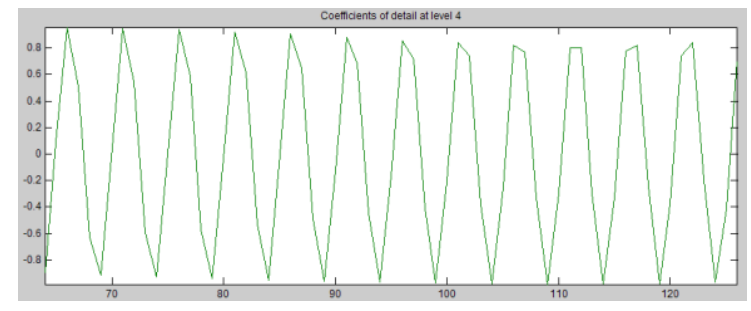

(a) Time

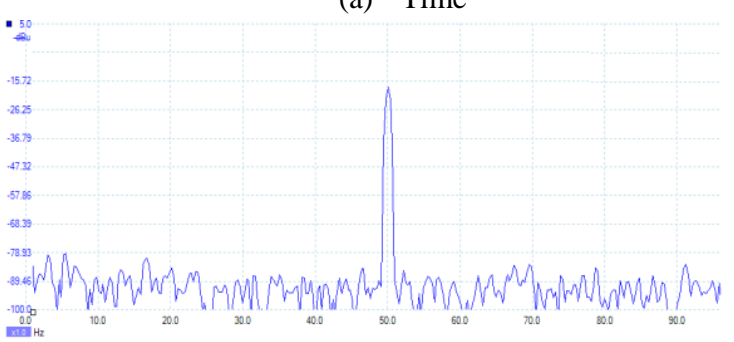

(b) Frequency

Figure 16. Experimental plots of stator current spectrum around fundamental of the healthy machine

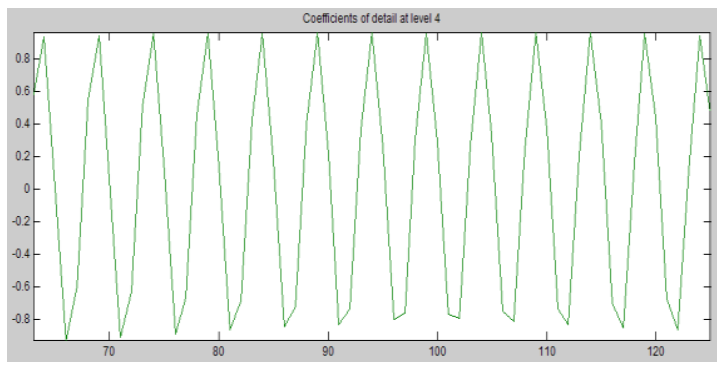

(a) Time

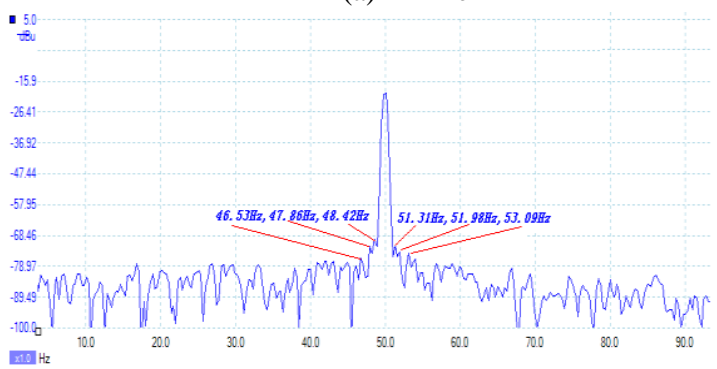

(b) Frequency

Fig17. Experimental plots of stator current spectrum around fundamental of the faulty machine with three broken bars

Table 4. Mean and standard deviation values of WT under healthy and three broken rotor bars

\begin{tabular}{|c|c|c|}
\hline \multicolumn{3}{|c|}{ Experimental Results } \\
\hline & Healthy & Three broken bars \\
\hline Mean abs & 0.2132 & 0.3572 \\
\hline Standard Deviation & 0.3517 & 0.4652 \\
\hline SD/Mean abs & 1.649624765 & 1.302351624 \\
\hline
\end{tabular}

Figure $16 \& 17$ show the time and frequency analysis of stator current under healthy and three broken rotor bars. From Figure 16(a)\&17(a), which show stator current wave under time domain, there is no obvious difference between these two. In contrast to Figure 16(a)\&17(a), Figure 16(a)\&17(a)are 
more obvious to judge the motor condition. According to the fault features frequency $(1 \pm 2 s) f$ equation, six frequencies appear around the fundamental frequency in Figure17(b).

Although frequency analysis has the ability diagnosis motor condition according to Figure 17 (b), the fault feature magnitudes are too small to detect and measure, sometimes even buried by the noise. This causes lot difficulties during industrial induction machine fault detection.

To avoid this problem and improve the detection result, the proposed approach is used in this experiment to decide the motor situation as shown in Table 4. The fault indices shown in Table 4 show a very accurate result coincide with the real situation. Comparing to Figure 17(b), quantification number have much more demonstration influence.

\section{CONCLUSION}

A detailed model of a squirrel-cage induction machine has been developed. In order to simulate broken rotor bars defects, the machine was modeled as a group of coupled magnetic circuits by considering the current in each rotor bar as an independent variable. The model has the ability to simulate the performance of induction machines during transient as well as at steady state, including the effect of rotor faults. Simulation and experimental data were analyzed to study rotor faults cause-effect relationship in the stator current and the current spectrum signature. A novel criterion was derived to assess rotor fault severity based on stator current. Simulations and experimental results confirm the validity of the proposed approach.

\section{REFERENCES}

[1] Chow, M. Y. Methodologies of using neural network and fuzzy logic technologies for motor incipient fault detection, World Scientific Publishing Co.Pte.Ltd,Singapore, 1997.

[2] Patton, R. J. and Chen,J. "On-line residual compensation in robust fault diagnosis of dynamic systems," in IFAC Symp Artificial Intelligence in Real-time Control, Delft, The Netherlands, no. 17, pp. 221-227, 1992.

[3] Bertenshaw, D. R., Smith, A. C.,Ho, C. W., Chan, T. andSasic, M. "Detection of stator core faults in large electrical machines," IET Electric Power Applications, vol. 6, no. 6, pp. 295-301, 2012.

[4] Walliser, R. F. and Landy, C. F. "Determination of interbar current effects in the detection of broken rotor bars in squirrel cage induction motors," IEEE Trans.Energy Conversion, vol. 9, no. 1, pp. 152-158, 1994.
[5] Ellison, A. J. and Yang, S. J. "Effects of rotor eccentricity on acoustic noise from induction machines," Proc.Inst.Electr.Eng, vol. 118, no. 1, pp. 174-184, 1974.

[6] Verma, S. P. and Natarajan, R. "Effects of eccentricity in induction motors," in Proc.Int.Conf.Electrical Machines,Budapest,Hungary, pp. 930-933, 1982.

[7] Morita, I. "Air-gap flux analysis for cage rotor diagnosis," Elec.Eng.In Japan, vol. 112, no. 3, pp. 171$181,1992$.

[8] Toliyat, H. A., Lipo, T. A. and White, J. C. "Analysis of a concentrated winding induction machine for adjustable speed drive application part 1 (Motor analysis)," IEEE Transaction on Energy Conversion, vol. 6, no. 4, pp. 679-684, 1991.

[9] Toliyat, H. A. and Lipo, T. A. "Transsient analysis of cage induction machines under stator rotor bar and endring faults," IEEE Transaction on Energy Conversion, vol. 10, no. 2, pp. 241-247, 1995.

[10] Ah-jaco, A. Modélisation des moteursasynchronestriphasés en régime Transitoire avec saturation et harmoniquesd'espace. Application au diagnostic," $\mathrm{PhD}$ thesis, Université de Lyon, juillet 1997.

[11] Munoz, A. R. and Lipo, T. A. "Complex vector model of the squirrel-cage induction machine including instantaneous rotor bar currents," IEEE-IAP, vol. 35, no. 6, 1999

[12] Lipo, T. A. and Toliyat, H. A. "Feasibility study of a converter optimized induction motor," Palo Alto,CA,Electric Power Research Institute,EPRI Final Rep, pp. 2624-02, 1989.

[13] Luo, X., Liao, Y., Toliyat, H. A., EI-Antably, A. and Lipo,T. A."Multiple coupled circuit modeling of induction machines," IEEE Transaction on Industry applications, vol. 31, no. 2, pp. 311-318, March/April 1995.

[14] AI-Nuaim, N. A. and Toliyat,H. A. "A novel method for modeling dynamic air-gap eccentricity in synchronous machines based on modified winding function theory," IEEE Transaction on Energy Conversion, vol. 13, no. 2, pp. 156-162, June 1998.

[15] Houdouin,G.,Baraket,G.,Dakyo,B.,Henao, H. and Capolino,G. A. "Coupled Magnetic Circuit Modeling of the Stator Windings Faults of Induction Machines Including Saturation Effect," In proceedings of the IEEE International Conference on industrial Technology(ICIT), pp. 148-153, 2004. 